\title{
Discoside, a Rare myo-Inositol-containing Glycolipid from the Caribbean Sponge Discodermia dissoluta
}

Lucia Barbieri, Valeria Costantino, Ernesto Fattorusso, ${ }^{*}$ Alfonso Mangoni

Dipartimento di Chimica delle Sostanze Naturali, Università di Napoli “Federico II”, via D. Montesano 49, 80131 Napoli, Italy

\section{SUPPORTING INFORMATION}

\section{Table of contents}

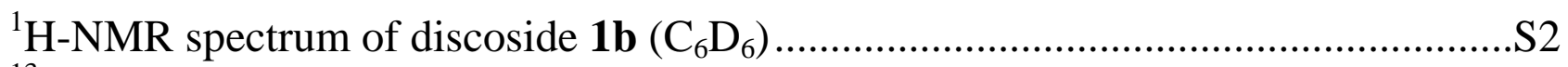

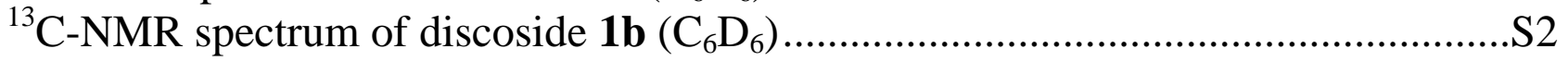

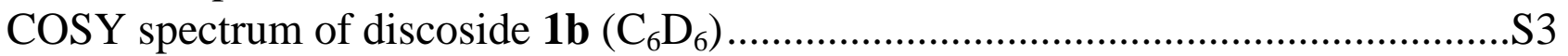

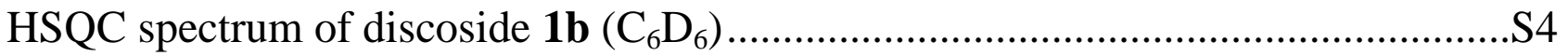

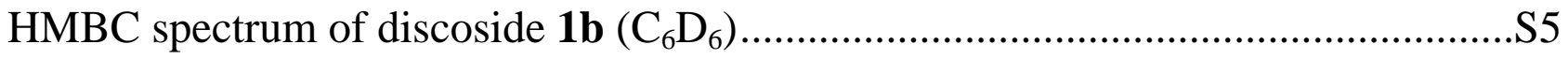

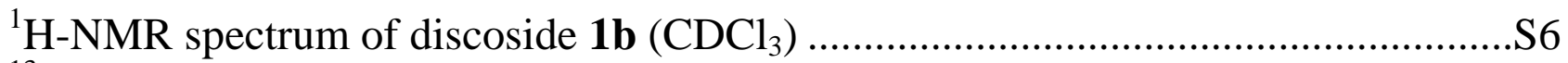

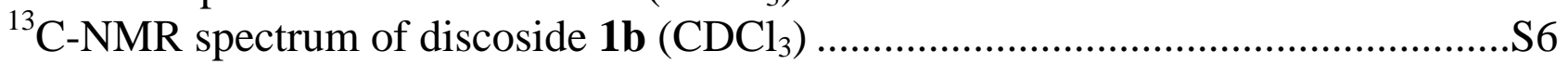

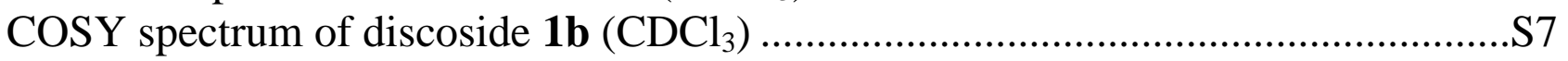

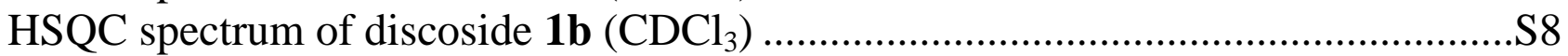

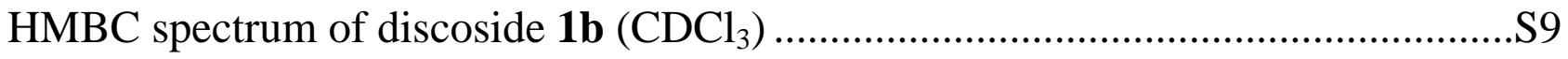

${ }^{1} \mathrm{H}$-NMR spectrum of methyl 2,3,4,6-tetra-O-benzoyl- $\alpha$-D-mannoside $\left(\mathrm{CDCl}_{3}\right) \ldots \mathrm{S} 10$ CD spectrum of methyl 2,3,4,6-tetra-O-benzoyl- $\alpha$-D-mannoside $\left(\mathrm{CH}_{3} \mathrm{CN}\right) \ldots \ldots \ldots . . . \mathrm{S} 10$ 
Discoside peracetate (1b)

$1 \mathrm{H}$ NMR (500 MHz)

C6D 6

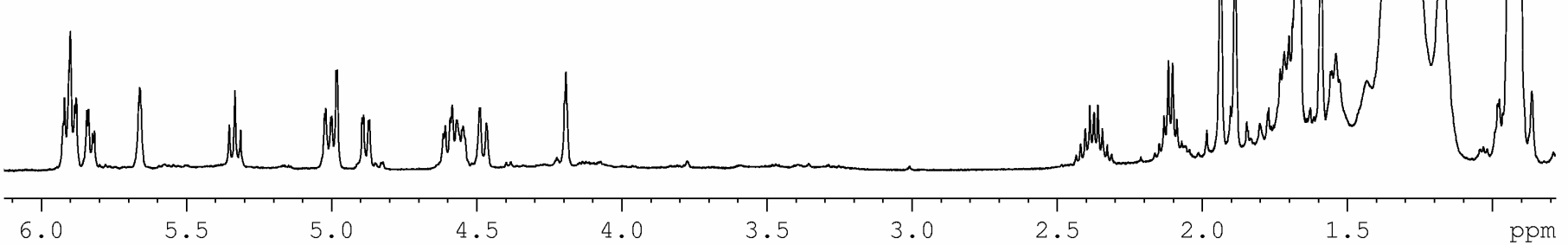

Discoside peracetate (1b)

$13 \mathrm{C}$ NMR

C $6 \mathrm{D} 6$

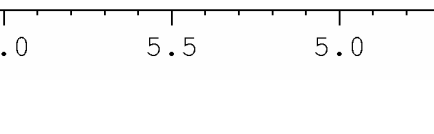

$170 \quad 160$

150

140

13

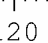

110
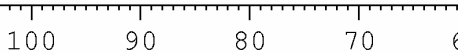

$60 \quad 50$

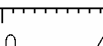

30

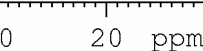


discoside peracetate (1b)

COSY

C6D 6

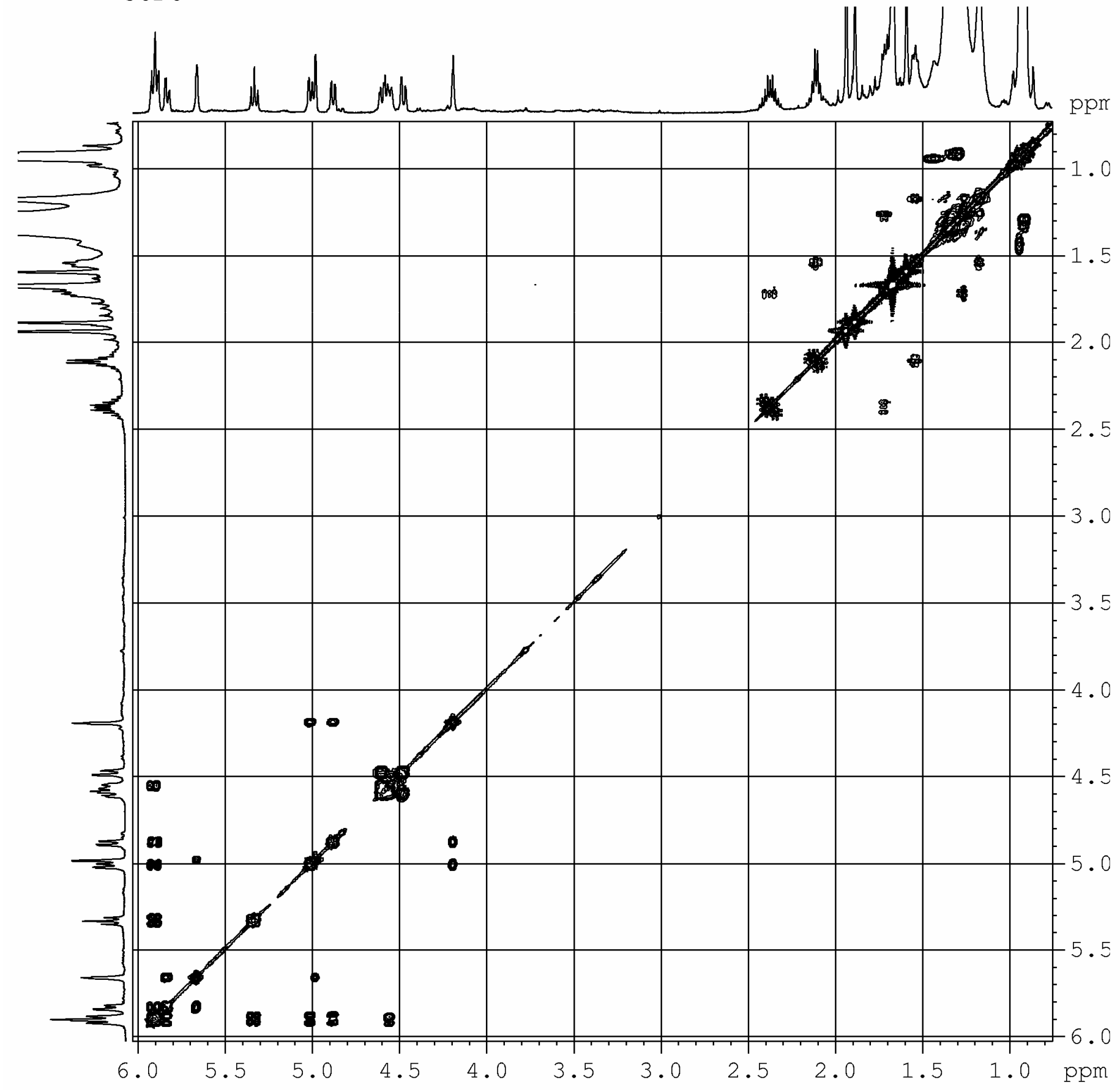


Discoside peracetate (1b)

HSQC

Benzene-d6

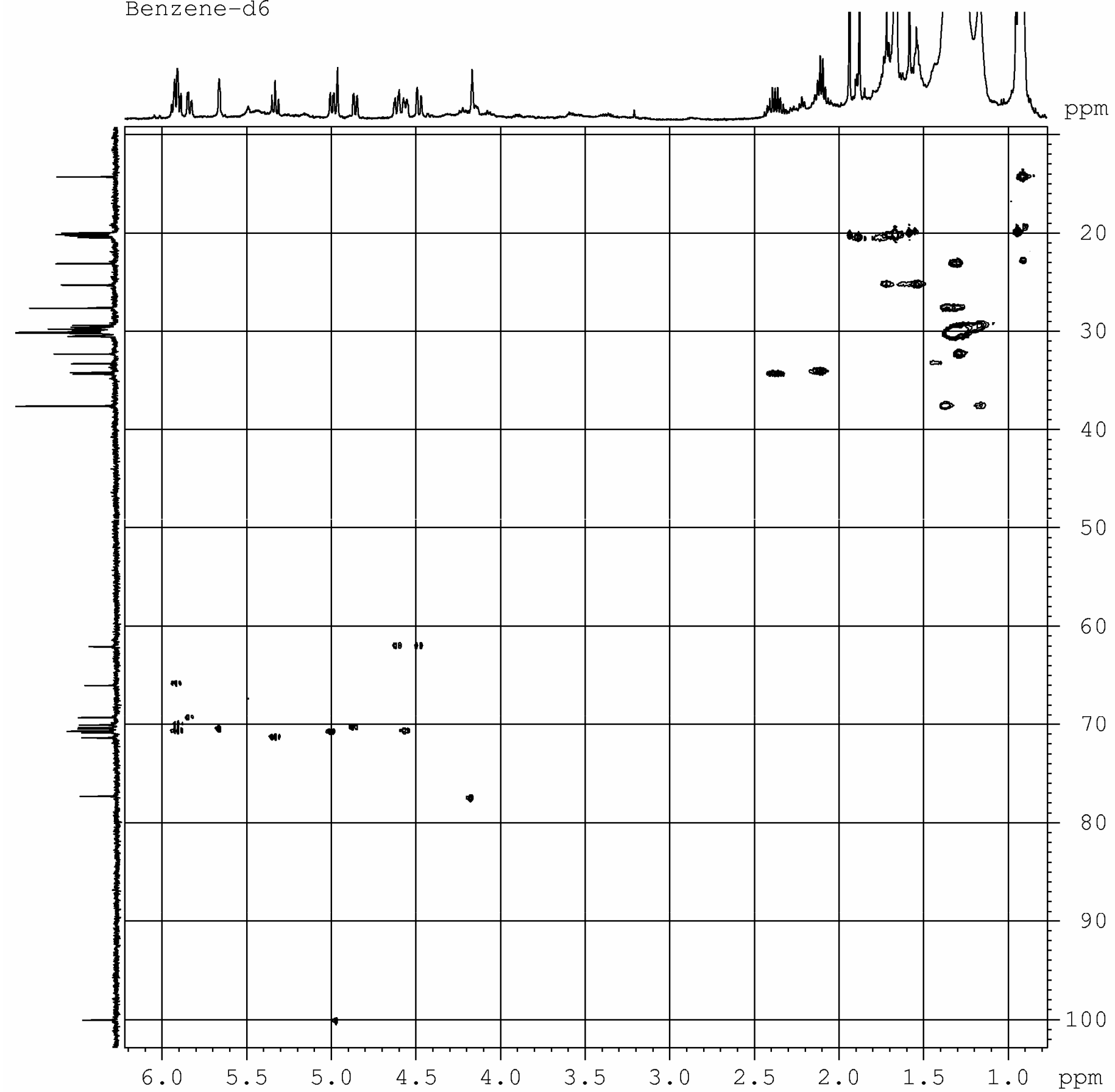




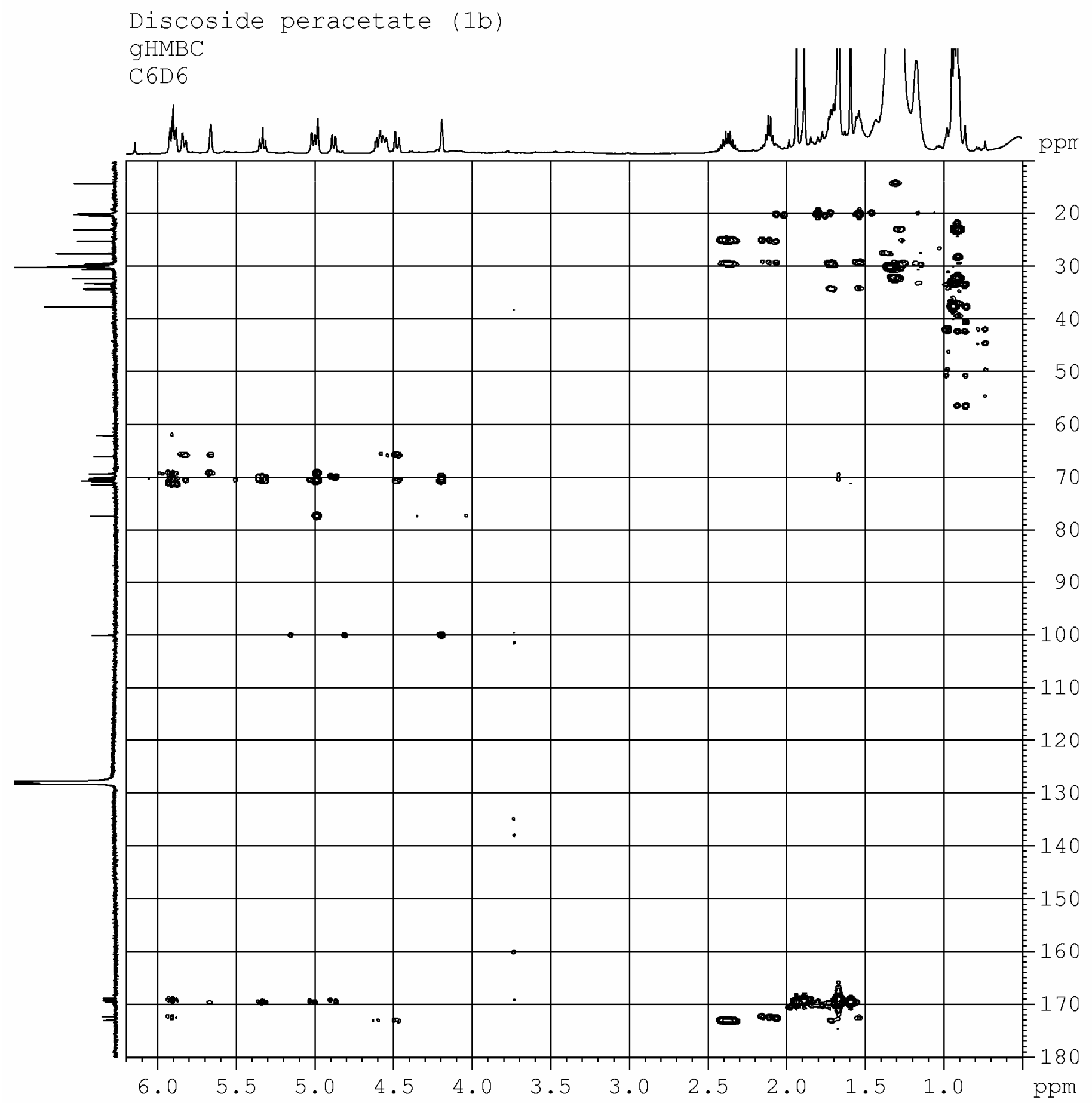


Discoside peracetate (1b)

$1 \mathrm{H} \mathrm{NMR}(500 \mathrm{MHz})$

$\mathrm{CDCl} 3$

Discoside peracetate (1b)

13C NMR

$\mathrm{CDCl} 3$

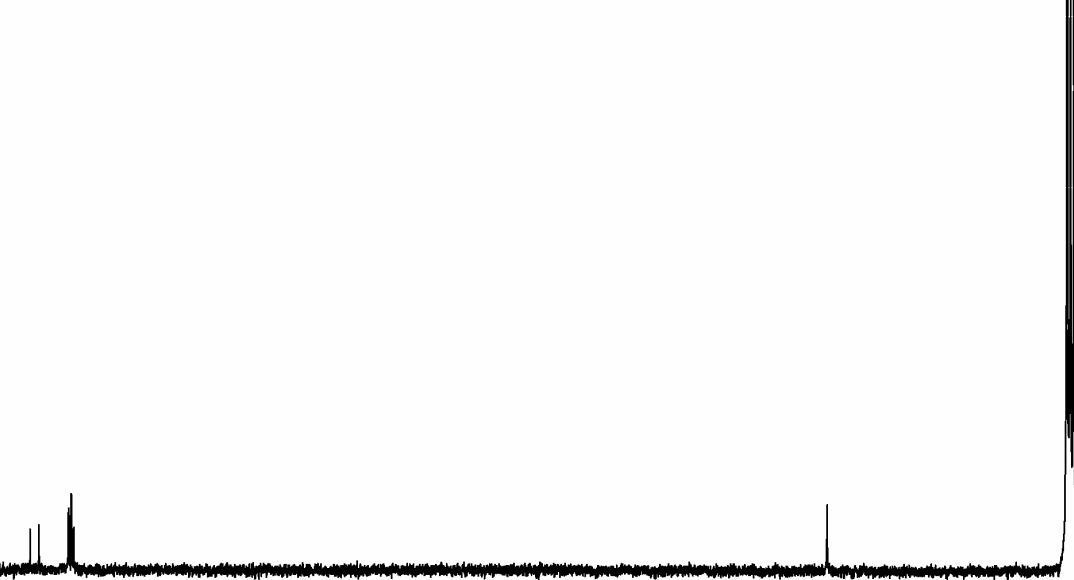

han
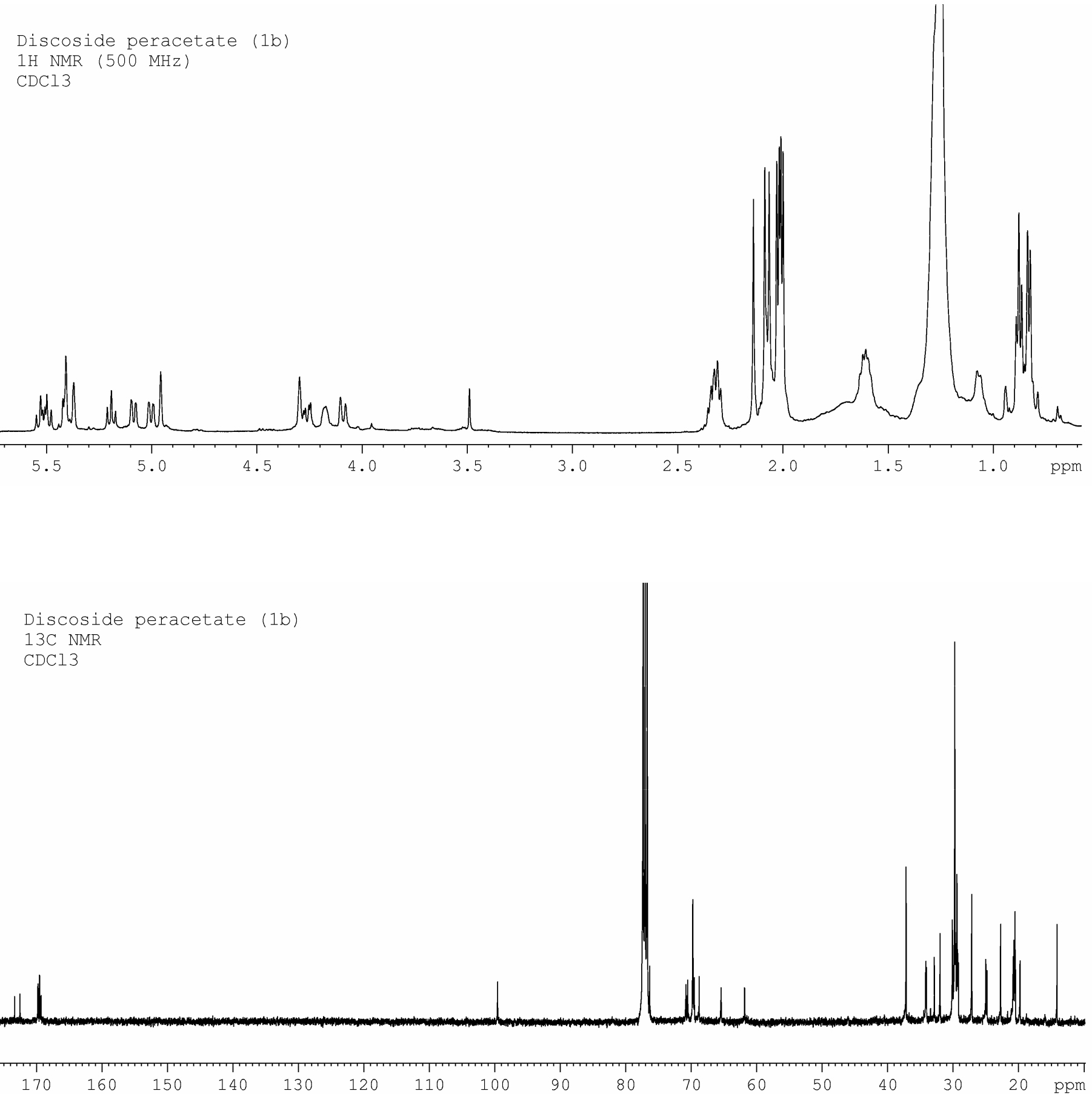
Discoside peracetate (1b)

COSY

CDCl3

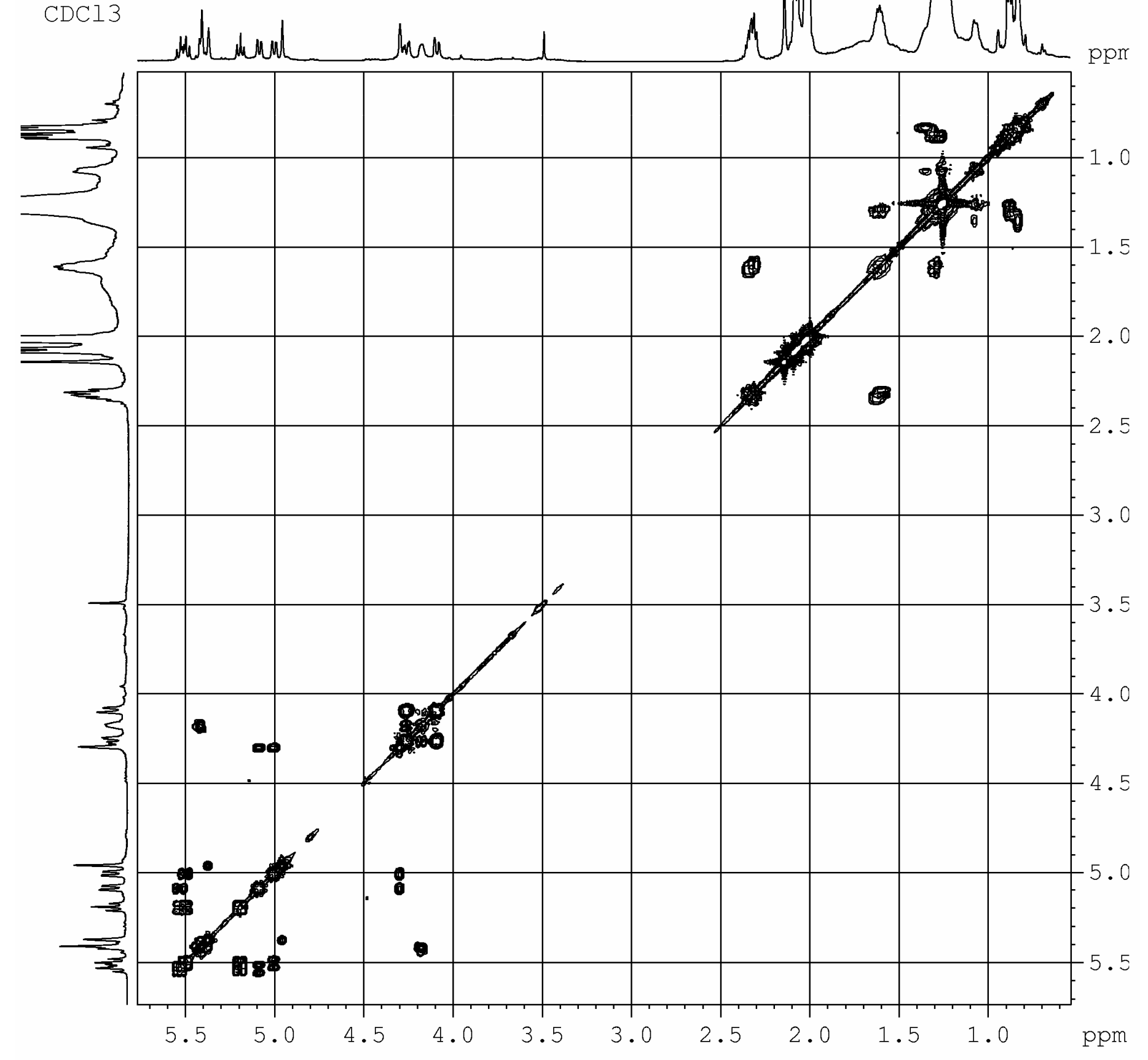


Discoside peracetate (1b) gHSQC

CDCl3

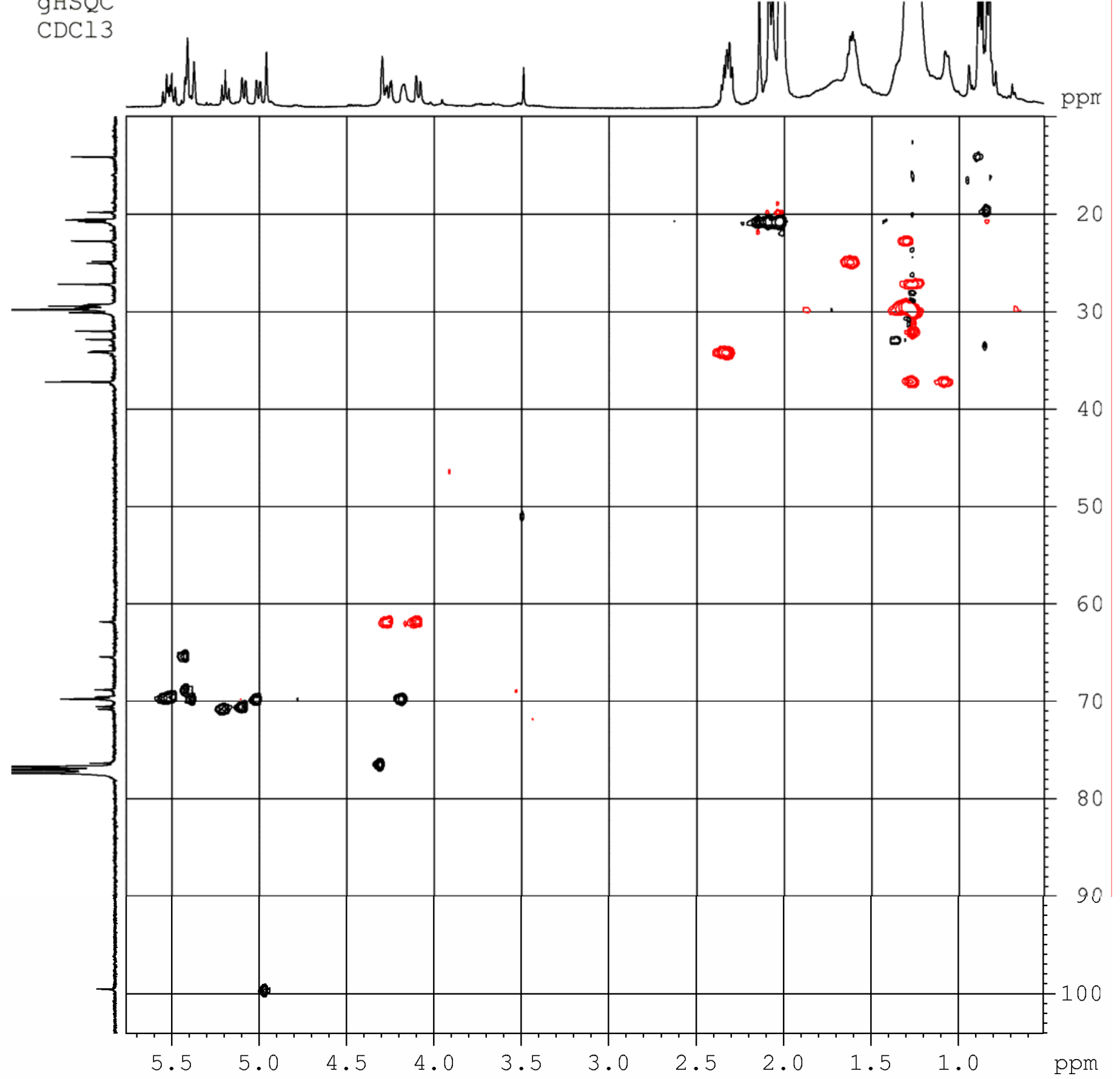


Discoside peracetate (1b) gHMBC

CDCl3

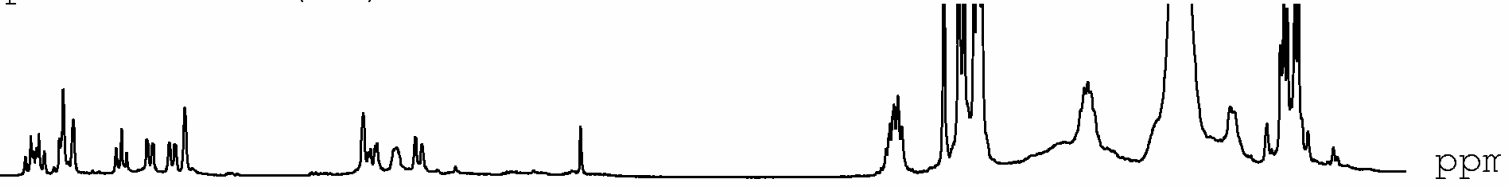

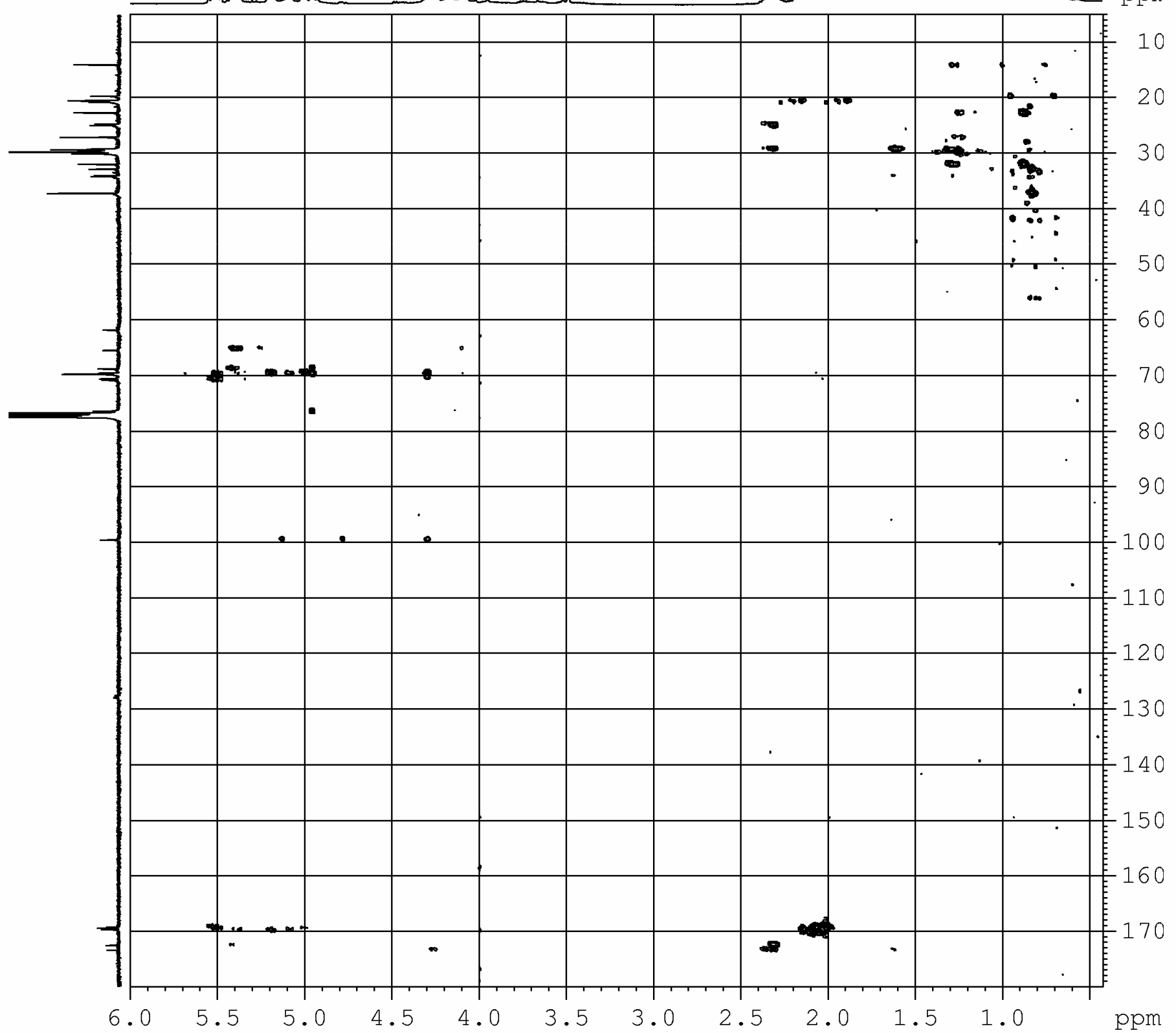


methyl 2,3,4,6-tetra-0-benzoyl-a-D-mannopyranoside

$1 \mathrm{H} \mathrm{NMR} \mathrm{(500} \mathrm{MHz)}$

$\mathrm{CDCl} 3$
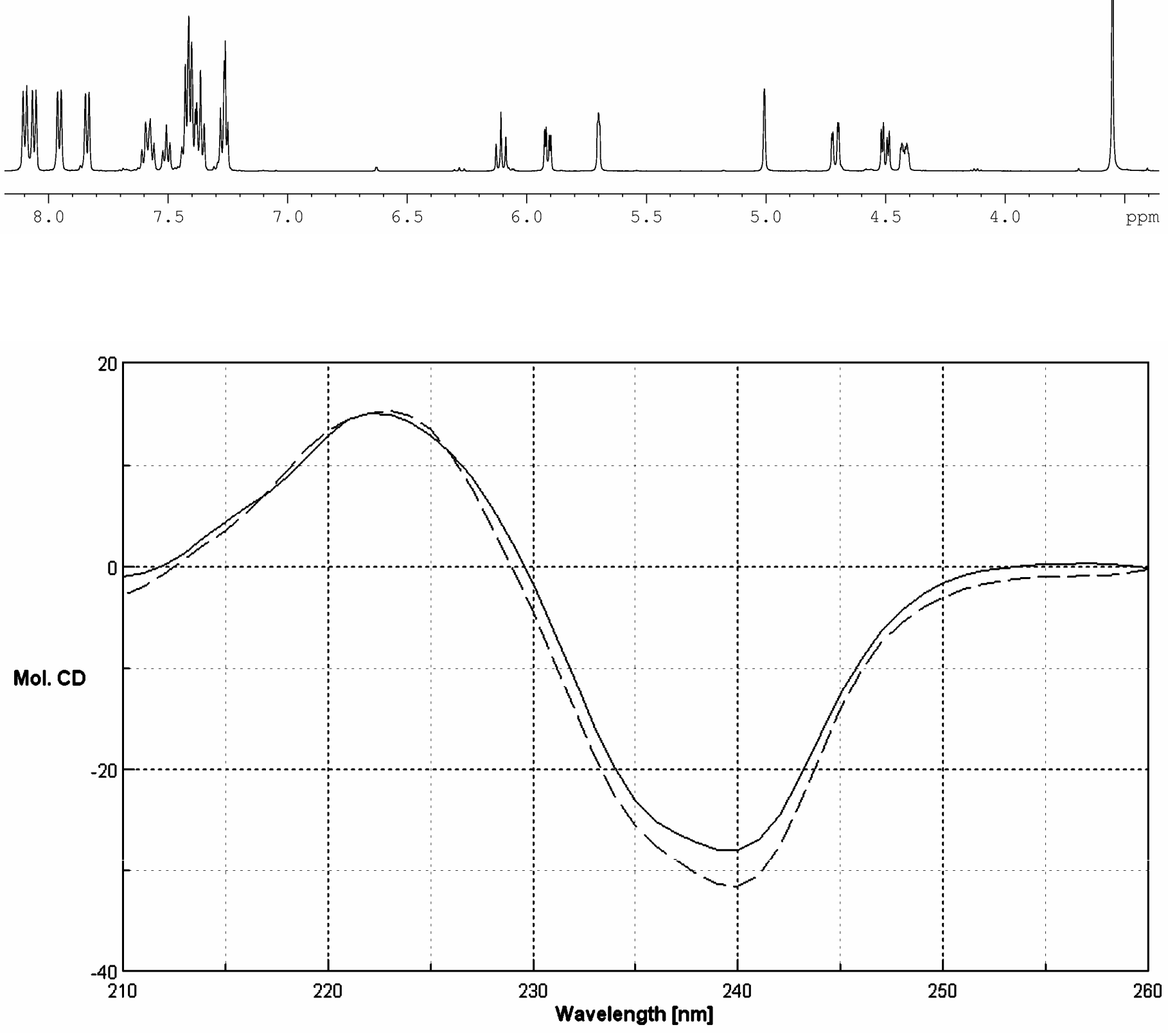